\title{
O Festival da Loucura e a promoção de práticas culturais ${ }^{1}$
}

\author{
Nadja Cristiane Lappann Botti \\ Doutora em Enfermagem Psiquiátrica (Universidade de São Paulo) \\ Professora da Universidade Federal de São João Del Rei. \\ nadjaclb@terra.com.br \\ Michele Cecília Silva Torrézio \\ Graduanda em Enfermagem (Universidade Federal de São João Del Rei). \\ micheletorrezio@yahoo.com.br
}

\begin{abstract}
Resumo No Brasil há premência de reverter o processo de exclusão da maior parcela do público das oportunidades de consumo e de criação cultural. A diversidade cultural coloca em pauta a questão da democratização cultural. Este artigo tem como objetivo refletir sobre em que aspecto o Festival da Loucura pode contribuir para a promoção de práticas culturais e democratização cultural. As edições do Festival apresentam incentivo a práticas culturais relacionadas a visitas a museu, centro cultural, exposição de artes plásticas, exibição de filmes nacionais e/ou estrangeiros, apresentação cênica e show musical. O Festival da Loucura caracteriza-se como um evento cultural que proporciona à comunidade local uma programação cultural diversificada ao longo de curto período de tempo, mediante atrações capazes de influenciar a imagem do local e oportunizar a inclusão e a democratização cultural.
\end{abstract}

Palavras-chave: cultura, inclusão, festival, saúde mental.

\section{Apresentação}

$\mathrm{D}$ esde 2oio, o Plano Nacional de Cultura (PNC) apresenta os princípios norteadores da política cultural do país (Brasil, 2010a). Em 2011, o Ministério da Cultura aprovou as metas do PNC, cuja implementação se dará ao longo da próxima década. Especificamente, a meta $\mathrm{n}^{\circ} 28$ prevê o aumento de $60 \%$ do número de pessoas que frequentam museu, centro cultural, cinema, teatro, circo e shows de dança e de música (Brasil, 2011a). No país, de acordo com pesquisa sobre práticas culturais, somente $7,4 \%$ da população visita mensalmente museu ou centro cultural; $14,2 \%$ frequentam teatro, circo ou show de dança; $18,9 \%$ assistem show de música e 18,4\% vão ao cinema (IPEA, 2010). Na contemporaneidade, considerando a demanda cultural, verifica-se a diminuição de visitas a espaços públicos culturais, em consequência das próprias características de complexificação da vida urbana, como disponibilidade de tempo, dificuldade no deslocamento e medo da violência (Canclini, 2000).

Sabe-se que os indicadores culturais são demonstrações parciais da realidade, pelo fato de a área cultural ser permeada por particularidades nem sempre tangíveis ou mensuráveis (Brasil, 2010b). As práticas cul-

1. O artigo faz parte do projeto de pesquisa História e Significados do Festival da Loucura de Barbacena, financiado pelo CNPq, edital MCT/CNPq No 014/2010 - Universal. 
turais, além de heterogêneas, também representam segregações socioeconômicas e espaciais. Neste sentido, o acesso à cultura apresenta-se como sintoma de outras desigualdades, ao mesmo tempo que produz distâncias sociais e culturais (IPEA, 2010). Destarte, as políticas culturais públicas devem ser capazes de atuar sobre essas desigualdades, favorecendo a criação de situações materiais que possam aumentar as possibilidades de fruição do tempo livre e democratizar o acesso a espaços, equipamentos, instituições e serviços de cultura (Botelho; Fiore, 2005).

Nesse caso, a elaboração de políticas deve partir da percepção da cultura como bem coletivo e das práticas culturais como ações de áreas diversas, como saúde, educação, meio-ambiente, planejamento urbano, entre outras (Botelho, 2001; Calabre, 2007). Ainda é importante observar as práticas culturais tanto como práticas propriamente ditas (ida a ópera/concerto de música clássica, balé/espetáculo de dança, teatro, cinema, museu/exposição e livraria/biblioteca) quanto como práticas de lazer e entretenimento (sair com amigos ou para dançar, almoçar ou jantar fora; frequentar cafés; ir à praia, ao shopping, a eventos esportivos etc., além das atividades que se praticam em casa, como ver televisão, ouvir rádio, ouvir música, ler jornais/revistas) (Brenner; Dayrell; Carrano, 2005).

Deste modo, a política cultural deve reconhecer a existência da diversidade de públicos, com visões e interesses diferenciados, que compõe a urbes contemporânea. No Brasil há premência de reverter o processo de exclusão das oportunidades de consumo e de criação cultural da maior parcela da população. Assim, a diversidade cultural coloca em pauta a questão da democratização cultural, notando que a cidadania democrática e cultural contribui para a superação de desigualdades e o reconhecimento das diferenças socioculturais existentes entre as pessoas (Calabre, 2007).

No Brasil, a política de atenção à saúde mental, a partir do processo da Reforma Psiquiátrica, também apresenta como princípios éticos a inclusão, a solidariedade e a cidadania. Especificamente, o objetivo maior da dimensão cultural da Reforma Psiquiátrica é a transformação do lugar social da loucura, da diferença e da divergência (Amarante, 2009). Um exemplo de experimentação dessa dimensão pode ser a criação do Festival da Loucura, realizado desde 2006 em Barbacena (MG) (Botti; Torrézio, 2012). A partir destas considerações, este artigo tem como objetivo refletir sobre os aspectos que o Festival da Loucura pode contribuir na promoção de práticas culturais e democratização cultural.

\section{O Festival da Loucura e a inclusão cultural}

Os indicadores sociais municipais do Censo Demográfico de 2010 apontam que Barbacena (MG) tem população de 126.284 habitantes, sendo 47,6\% homens e 52,4\% mulheres. Dessa população, 91,5\% moram na zona urbana e $8,5 \%$, na zona rural. O valor médio do rendimento mensal domiciliar per capita nominal foi de $\mathrm{R} \$ 672,00$, e a taxa de analfabetismo da população de 15 anos ou mais de idade, 5,5\% (IBGE, 2010).

O Festival da Loucura teve sua primeira edição em 2006 e caracteriza-se como evento cultural, artístico e científico, com programação diversificada e gratuita nas principais ruas e praças de Barbacena. A diversificação das atividades da programação das edições do Festival dá visibilidade à sociedade acerca do tema da loucura, para além do espaço restrito de tratamento ao qual encontrava-se fortemente relacionado. O Festival é realizado anualmente durante quatro dias e organizado pela gestão pública municipal e estadual. Entre os organizadores participam a Secretaria Municipal de Cultura, representada pela Empresa Municipal de Turismo (Cenatur) e Fundação Municipal de Cultura de Barbacena (Fundac); Secretaria Municipal de Saúde, por meio do Departamento Municipal de Saúde Pública (Demasp); e Secretaria Estadual de Saúde, representada pela Fundação Hospitalar de Minas Gerais (Fhemig) e pela Coordenação de Saúde Mental.

Historicamente, Barbacena foi sede do primeiro hospital psiquiátrico de Minas Gerais, o Hospital Colônia de Barbacena, que cumpriu seu papel com o tratamento adequado para a época, da inauguração em 1903 até 1930 (Vidal; Bandeira; Gontijo, 2008). Entretanto, após esse período, tornou-se referência para internação de pacientes de várias regiões do estado. Gradativamente a situação do hospital-colônia de Barbacena tornava-se pior, e na década de 1950 caracterizava-se por pavilhões em ruínas e com uma superlotação em torno de 300 a 400\% superior à sua capacidade (Magro Filho, 1992). Com o aumento do número de pacientes, os leitos ficaram insuficientes e a escassez de recursos financeiros, materiais e principalmente humanos, tornou-se um grave problema. $\mathrm{O}$ tratamento dispensado aos pacientes passou a ser desumano e degradante, atingindo elevadas taxas de mortalidade. Nessa época, o hospital psiquiátrico tornou-se depósito de pacientes, entreposto de comércio de cadáveres, e por isso Barbacena ganhou o estigma de "Cidade dos Loucos" (Pereira, 2009). Na história do hospital contabilizam-se mais de 60 mil mortes, cujas principais causas são infecção intestinal e pulmonar, fome e frio (Magro Filho, 1992). 
Segundo Foucault (2007), a internação de loucos como prática social é tipicamente moderna e nasceu de uma dupla necessidade das sociedades industriais capitalistas emergentes. Por um lado, da necessidade de saneamento e ordenação do espaço urbano, pela distribuição e controle da circulação dos indivíduos; por outro, da necessidade de disciplinar seus corpos e mentes, por meio da criação e proliferação de instituições apropriadas. É nesta categoria que se enquadra a instituição psiquiátrica em seu modelo asilar originário, que se consolidou ao longo do século XIX, perdurando de forma quase inalterada em seus fundamentos até meados do século XX.

Com a arqueologia foucaultiana, percebe-se que a loucura não é o contraponto da razão, ao menos a partir da era clássica. A loucura foi paulatinamente sendo incorporada à razão. E se há alguma forma de resistência, esta se dá nas outras formas da desrazão (ou do desatino), que não aquelas submetidas ao confinamento. É neste aspecto que se pode assinalar uma aproximação entre as ideias de Foucault e a Reforma Psiquiátrica, a partir da crítica ao enclausuramento da loucura sustentado pelo poder médico (Sander, 2010).

Ressalta-se que a ideia de manicomial baseia-se, como adverte Foucault (2007), em uma invenção da loucura como doença mental que necessita de tratamento fundamentado na moralidade e na medicamentação, e cujo investimento de cuidado encontra-se voltado para a doença, e não para os sujeitos da experiência. Já o paradigma antimanicomial desenvolve várias ações que buscam transformar o imaginário social em relação à loucura, à doença mental, à anormalidade. Essas ações referem-se a um conjunto de práticas sociais que possam construir solidariedade, inclusão dos sujeitos em desvantagem social, diferença e diversidade (Amarante, 1999).

A partir da década de 1970, por causa da reação de profissionais de saúde, jornalistas e intelectuais, iniciou-se em Barbacena a reavaliação das condições de tratamento vigentes e o questionamento da loucura como desrazão (Vidal; Bandeira; Gontijo, 2008), em consonância com os pressupostos de formulação crítica e prática visando à transformação do modelo clássico e do paradigma psiquiátrico (Amarante, 1997).

Pode-se pensar que também foi a apropriação das ideias de Foucault que tornaram possível a catalisação de pensamentos, críticas e ações, contribuindo com a Reforma Psiquiátrica e o progressivo desmonte do manicômio (Sander, 2010). Um ponto em comum entre a crítica foucaultiana e a Reforma Psiquiátrica é o questionamento do manicômio, ou hospital psiquiátrico. Espaço por excelência do poder médico, o hospital (o tratamento em regime fechado) é questionado por sua ineficiência, pela alienação perpetuada aos internos, pela desumanização etc. (Sander, 2010).
É neste ponto que o Festival da Loucura pode ter encontrado importantes ressonâncias no pensamento foucaultiano: a loucura, antes emudecida, pode ter voz; antes enclausurada e excluída da sociedade, pode ter liberdade e cidadania. Importante ressaltar que não houve influência direta de Foucault na criação do Festival da Loucura, mas é inegável a importância das ideias desse pensador para o entendimento do evento.

Sabe-se que abordar as experiências da loucura pensando em sua presença e produção no espaço sociocultural é um dos pontos fundamentais desse processo, que prima por mudanças profundas não somente nos aspectos jurídicos, políticos e assistenciais, mas, sobretudo, nos valores e significações sociais em torno da loucura e do louco (Passos, 2003). Apesar do estigma da cidade e do tema da loucura em geral serem tratados com restrições, o Festival da Loucura pode representar uma ocasião em que a Barbacena assume o título de "Cidade dos Loucos", com conotação diversa da reconhecida, de acordo com a história (Botti; Terrézio, 2012).

A transformação do imaginário social, isto é, do lugar social da loucura, que historicamente encontra-se relacionada com a incapacidade do doente mental em estabelecer relações sociais e simbólicas, é importante objetivo da dimensão sociocultural da Reforma Psiquiátrica. Neste sentido, torna-se estratégica a produção de um conjunto de ações que visam à transformação desse imaginário social, que logo poderá modificar as relações estabelecidas entre sociedade e loucura (Amarante, 2008). Em nível nacional, existe a política pública Loucos pela Diversidade, desenvolvida pelo Ministério da Cultura, que dá visibilidade às produções das pessoas com transtorno mental. Neste caso, as edições do Festival são, em nível regional, exemplo de novas práticas e ações que utilizam a linguagem artística para a transformação do imaginário social.

Em geral os festivais geram desenvolvimento local, considerado como a articulação entre as atividades culturais, políticas, econômicas, transformando de forma consciente a realidade local (Milani, 2005 apud Petitinga, 2008). Segundo Canclini (2005, p. 185), as atividades culturais tem papel preponderante no desenvolvimento local: "Mais recentemente vem se entendendo que os recursos culturais, a atenção à diversidade de culturas presentes em cada urbe e a promoção da arte, os espetáculos e os meios de comunicação podem contribuir decisivamente para o desenvolvimento das cidades".

Os contrastes socioeconômicos da população brasileira também se manifestam na desigualdade do acesso a bens, produtos, serviços, informações, meios de produção e espaços públicos de cultura (Cazelli, 2005). Sabe-se que a indústria cultural promove intensa circulação de informações e bens culturais, o 
que não significa a possibilidade de enriquecimento da vida das pessoas ou de autonomia na escolha de como desejam viver. Deste modo, a riqueza cultural contemporânea implica consideráveis desigualdades, tanto na sua fruição quanto na sua produção. A estrutura das distribuições sociais, por outro lado, impede as possibilidades de reconhecimento social e o estabelecimento de vínculos, dados o isolamento das esferas de sociabilidade e a privatização dos consumos. Os dois argumentos indiciam a pobreza cultural, seja pela exclusão de oportunidades substantivas de acesso a bens simbólicos seja pela retração dos espaços de sociabilidade.

O consumo cultural mantém relações com a cidadania, pois se refere a uma das dimensões do acesso a certos bens e serviços que é ponto central dos direitos culturais, entendendo-se o direito à cultura entre todos os demais direitos, isto é, civil, político e social (Silva; Araújo; Silveira, 2007). No Brasil, entre os obstáculos encontrados para o acesso à oferta cultural encontram-se os preços altos como ponto importante de empecilho à fruição de bens culturais (IPEA, 2010). Diante disto, questiona-se: como o Festival da Loucura pode contribuir para o consumo cultural e favorecer as práticas culturais?

Nas cinco edições do Festival da Loucura, realizadas entre 2006 e 2010, identifica-se programação cultural gratuita, com mostra de filmes, apresentação de peças teatrais e shows musicais, exposição de artes plásticas, entre outros. Neste caso, pode-se pensar que o evento oportuniza o consumo cultural. Outro dado importante refere-se ao fato de que grande parte das práticas culturais no país não é realizada pela população. Neste sentido, dados nacionais destacam que $59,3 \%$ das pessoas nunca vão a teatro, circo ou apresentações de música; $54 \%$ jamais frequentam cinema e $51,5 \%$ nunca assistem a shows de música (IPEA, 2010).

\section{Práticas culturais e o Festival da Loucura}

Na região Sudeste, 92,9\% das pessoas raramente ou nunca visitaram um museu ou centro cultural, enquanto $4,2 \%$ visitam esses locais pelo menos uma vez por mês (IPEA, 2010). Observa-se que a programação das edições do Festival da Loucura mostra incentivo a práticas culturais relacionadas a visitas ao museu ou centro cultural. Entre essas, identifica-se o Centro Ferroviário de Cultura (Cefec), que na época do Festival funciona como centro cultural. No Cefec, durante o Festival, visita-se o projeto Doidos por Arte, com exposição de trabalhos de artistas loco-regionais e de artistas vinculados a instituições psiquiátricas de Barbacena. Entre estes, citam-se os quadros de pacientes e de Xico Santeiro, ex-funcionário do Centro Hospitar Psiquiátrico de Barbacena, abordando o tema da loucura e das instituições psiquiátricas (Fonseca, 2006; Maglioli, 2006; Pelegrini, 2007; Beghini, 2007). Outra iniciativa do Festival da Loucura refere-se à exposição do acervo do Museu do Inconsciente e do Museu Bispo de Rosário (Fonseca, 2006; Maglioli, 2006), museus cariocas que preservam trabalhos produzidos por internos do Centro Psiquiátrico Pedro II e da Colônia Juliano Moreira. O Festival promoveu ainda a mostra do profeta Gentileza (1917-1996) e do programa nacional De Volta Pra Casa (Fonseca, 2006; Maglioli, 2006), que tem por objetivo garantir assistência, acompanhamento e integração social a de pessoas, fora do hospital, acometidas por transtornos mentais, com história de longa internação psiquiátrica.

No Festival também se podem visitar as esculturas de Dom Quixote, Sancho Pança e do cavalo Rocinante, de Mário Mendonça, artista contemporâneo que apresenta o potencial transformador da arte, produzindo esculturas com o aproveitamento de material da coleta seletiva. Encontra-se ainda a escultura Fazedor de Montanhas, de Sílvio Galvão e Sandro Rodrigues, construída com isopor, espuma de poliuretano, papel e outros materiais reaproveitados.

Em Minas Gerais, somente 18,41\% dos municípios declaram ter museus (Brasil, 2010b). Barbacena conta atualmente com quatro museus, sendo todos de natureza público municipal: o Museu Georges Bernanos é o mais antigo, tendo sido criado em 1968; o Museu da Loucura, criado em 1996 e que funciona no antigo manicômio; o Museu Municipal de Barbacena, criado em 1999; e o Parque Museu Casa de Emeric Marcier, o mais novo da cidade, criado em 2004 (Brasil, 2011).

O Museu da Loucura teve a reinauguração da sua expansão e reforma durante a terceira edição do Festival, em 2008. Esse museu participa do plano de resgate da memória da cidade, mostrando a história do antigo manicômio e da atual abordagem do tratamento psiquiátrico. Assim, acredita-se que atue proporcionando abertura para comunidade aceitar o doente mental (Silva, 2009).

Pesquisa nacional revela que $54 \%$ da população nunca frequentou cinema e que $26 \%$ o faz raramente; por outro lado, $9 \%$ vão ao cinema pelo uma vez por mês (IPEA, 2010). Minas Gerais, segundo a Agência Nacional do Cinema (Ancine), conta com 192 salas de projeção, instaladas em 8,56\% dos municípios. Barbacena possui duas salas de projeção, localizadas no shopping center. Em relação ao perfil do consumidor brasileiro, verifica-se que os filmes vistos com mais frequência são de produção norte-americana 
(19\%). Entre os gêneros são mais assistidos estão os filmes de ação e aventura (15\%) e comédias (14\%). Somente $3,9 \%$ da população relata assistir filme nacional (Brasil, 2010b).

Como visto, as práticas culturais relacionadas a visitas aos museus ou ao centro cultural também se verificam nas programações culturais das edições do Festival da Loucura, durante a exibição de filmes nacionais e estrangeiros. Essa iniciativa faz parte do projeto Cinema na Praça, com exibição de filmes à tarde e à noite na Praça dos Andradas ou na Praça da Estação.

$\mathrm{Na}$ programação encontram-se filmes temáticos sobre loucura/psiquiatria/saúde mental, como Um Estranho no Ninho, K PAX - O Caminho da Luz, Jornada da Alma, Bicho de Sete Cabeças, Leolo (Fonseca, 2006; Maglioli, 2006), Cheiro do Ralo, Estamira, Omissão de Socorro (Beghini, 2007; Nunes Filho, 2008), Se eu fosse você 2, As alegres Comadres, Piaf - Um Hino ao Amor, Deu a louca na Chapeuzinho, Saneamento Básico e Vida de Menina (Reis, 2009; Resende, 2009).

No Brasil, 59,3\% das pessoas nunca frequentaram teatro, circo ou apresentações de música (IPEA, 2010). A Região Sudeste concentra os estados com a maior quantidade de teatros, especialmente pela influência de São Paulo (306 teatros) e do Rio de Janeiro (231 teatros), sendo que Minas Gerais conta com 132 teatros. No país, 25,8\% dos municípios declararam realizar festivais/mostras de teatro, mas esse percentual cai para 20,63\% nos municípios mineiros. Ainda é possível constatar que 21,2\% dos municípios declararam possuir teatros/salas de espetáculo, sendo que em Minas Gerais esse percentual se reduz para 19,23\% (Brasil, 2010b). Barbacena, particularmente, conta somente com o teatro da Associação Cultural Ponto de Partida, do grupo teatral Ponto de Partida, formado em 1980.

As edições do Festival da Loucura exibem peças teatrais. O teatro é capaz de contribuir acentuadamente para o desenvolvimento sociocultural e educativo loco regional, tanto nos aspectos da participação das populações na vida cultural quanto na fruição de práticas artísticas ou no aumento potencial dos hábitos culturais (Rodrigues Júnior, 2008). As apresentações das performances, dramatizações e peças teatrais foram realizadas por grupos artísticos de expressão nacional, além dos grupos de Barbacena e região. As apresentações foram realizadas à tarde e à noite, na Praça dos Andradas e na Praça da Estação, ou Cefec.

Entre os artistas barbacenenses, verifica-se presença dos grupos Carpe Diem (Fonseca, 2006; Maglioli, 2006), Cenarte (Pelegrini, 2007; Beghini, 2007), Ponto de Partida (Fonseca, 2006; Maglioli, 2006; Nunes Filho, 2008; Resende, 2008) e Bar de Papo (Reis, 2009; Resende, 2009). O Festival conta também com grupos teatrais de Belo Horizonte como a Companhia Faminta de Teatro, o grupo Cine Horto na Estrada (Pelegrini, 2007; Beghini, 2007), o Grupo Galpão (Nunes Filho, 2008; Resende, 2008) e o Teatro de Bonecos Giramundo (Maglioli, 2010; Resende, 2010) - e de outras cidades mineiras, como a Companhia de Teatro ManiCômicos (Reis, 2009; Resende, 2009).

Interessante observar que a $5^{\text {a }}$ edição do Festival (2010) contou com a apresentação da Trupe Gaia, grupo de artistas de Belo Horizonte fundado em 2006, que tem como proposta a prática e a difusão da consciência ambiental mediante artes circenses e teatro, que promoveu a oficina de Atividades Circenses na Praça da Estação (Maglioli, 2010; Resende, 2010).

$\mathrm{Na}$ atualidade, o fazer e o assistir espetáculo teatral ainda tem sido difícil e excludente, apesar das leis de fomento e apoio estabelecidas pelas políticas públicas. Como visto, a programação do Festival da Loucura conta com apresentações cênicas, importante iniciativa, pois os festivais podem atuar como espaços para o surgimento de novos talentos e ideias e de estímulo à formação de grupos teatrais. Além disso, podem estimular o público para a apreciação das artes cênicas, ao possibilitar apresentações tanto a consumidores habituais de cultura quanto a não habituais. Neste sentido, os festivais democratizam o acesso à produção de bens e serviços culturais (Rodrigues Júnior, 2008).

A grande originalidade das peças teatrais apresentadas no Festival da Loucura é privilegiar o estético, associado ao panorama social em que o teatro deve integrar-se. Outra questão importante reside no fato de o teatro apresentar linguagem que possibilita uma reflexão sobre a realidade (Rodrigues Júnior, 2009). Neste sentido, ressalta-se a importância da apresentação, na $3^{\text {a }}$ edição do Festival da Loucura (2008), do espetáculo teatral "Camille Claudel: tem Sempre Algo de Ausente que me Perturba", do Grupo Quadrante (Nunes Filho, 2008; Resende, 2008). Esse grupo cênico surgiu em 2003 com a proposta de dar sequência ao trabalho de Nise da Silveira e Rubens Correa na inserção do teatro como ferramenta para ressocialização de pacientes dos hospitais psiquiátricos.

No Brasil, 58,8\% da população ouve diariamente rádio/música e $25,5 \%$ pelo menos uma vez por mês; por outro lado, 51,5\% nunca frequentam shows musicais (IPEA, 2010). Apesar disto, 38,7\% dos municípios mineiros realizam festivais/mostras de música (Brasil, 2010b). Na programação cultural do Festival da Loucura há apresentação de shows musicais, realizados à noite na Praça dos Andradas ou na Praça da Estação. Neste sentido, o Festival da Loucura pode configurar-se como vitrine para a divulgação da música independente e de novos talentos musicais, por 
atrair público considerável, heterogêneo e pela possibilidade de artistas consagrados dividirem o mesmo espaço com músicos que estão surgindo no mercado. Outro fato importante refere-se à apresentação musical de grupos de instituições psiquiátricas. Para muitos artistas, os festivais são oportunidade para contato com público novo, para usufruir a repercussão e a qualidade técnica do evento. Ademais, esse ambiente possibilita acompanhar de perto as novidades e o trabalho de outros artistas (Bianchin; Maughan, 2004 apud Petitinga, 2008).

Neste sentido, a programação cultural do evento contou com a participação dos músicos Amorim Menezes (Fonseca, 2006; Maglioli, 2006), Legião Urbana Cover (Pelegrini, 2007; Beghini, 2007), Rodrigo Nézio, Duo Conde Blues, Cazuza Cover, bandas Luxúria, Manacá (Nunes Filho, 2008; Resende, 2008), bandas Lúdica Música, Balaio de Gato, Casa de Orates, Mellon Chip (Reis, 2009; Resende, 2009) e Bandas Sheik Loko, Cacharrel, Pré Pagos e The Yellow Brick Road (Maglioli, 2010; Resende, 2010). Entre os músicos consagrados, promoveu shows com Lobão, Hermeto Paschoal, Tom Zé (Fonseca, 2006; Maglioli, 2006), Paulinho Moska e Arnaldo Antunes (Pelegrini, 2007; Beghini, 2007), Pitty, Marcelo D2 (Nunes Filho, 2008; Resende, 2008), Zélia Duncan, Martinália (Reis, 2009; Resende, 2009) e Zeca Baleiro (Maglioli, 2010; Resende, 2010).

Como a grande maioria dos festivais no Brasil, principalmente os mais antigos e consolidados, monta sua grade de programação baseada em artistas já renomados e que trazem grande público, é importante constatar a importância dada aos músicos locais e independentes quando incluídos na grade da programação, pois em geral não são conhecidos e, por isso, necessitam de uma vitrine para expor seu trabalho (Petitinga, 2008).

Na programação cultural do Festival da Loucura também houve a apresentação do Bloco Tirando a Máscara, da Fhemig. Esse bloco foi idealizado por profissionais da Fundação no carnaval de 1998, partindo do pressuposto da importância da reinserção dos doentes mentais na comunidade. $\mathrm{O}$ evento contou ainda com a apresentação do Trem TanTan, grupo musical formado por pacientes com transtorno mental do Centro de Convivência de Venda Nova, de Belo Horizonte, sob coordenação do artista Babilak Bah (Fonseca, 2006; Maglioli, 2006). O Bloco Tirando a Máscara e o grupo Trem TanTan são exemplos mineiros da Reforma Psiquiátrica e da inclusão social do doente mental. $\mathrm{Na} 2^{\mathrm{a}}$ edição do Festival ocorreu a apresentação da banda Sistema Nervoso Alterado (Pelegrini, 2007; Beghini, 2007). Essa banda foi criada em 1999, no Rio de Janeiro, com o objetivo de intermediar, por meio da arte, as relações sociais de pessoas com transtorno mental.

\section{A formação da imagem local, por meio da cultura, no Festival da Loucura}

A literatura acerca dos festivais discute o significado desses eventos para a construção da imagem do local (Petitinga, 2008; Rodrigues Júnior, 2008). Chwe (1998 apud Petitinga, 2008) afirma que eventos públicos como os festivais apresentam importante papel na criação de um conhecimento comum e na promoção de incentivos sociais para os residentes se envolverem nas atividades comunitárias, reforçando a comunicação social e os laços com a comunidade. Neste sentido, os festivais caracterizam-se pelo compromisso e pela integração com a comunidade local.

Uma das contribuições dos festivais para a imagem local refere-se à possibilidade de reverter uma imagem negativa. Neste caso, é uma das finalidades do Festival da Loucura, desde sua $1^{a}$ edição em 2006, preservar a história de Barbacena como "Cidade dos Loucos" e desmitificar a doença mental mediante uma abordagem artística, intelectual e social. As cinco edições do Festival ocorreram de quinta a domingo, com atividades em diferentes locais e horários, distribuídas em programação cultural e científica.

Historicamente, Barbacena, após perder para Belo Horizonte a disputa de nova capital mineira, recebeu como prêmio político de consolação um dos primeiros manicômios brasileiros. Desde então, muitos "trens de doido" desembarcaram na cidade, lotados de doentes mentais, nome que abrangia desde pessoas com transtornos mentais propriamente ditos como outros tipos de desviantes sociais (vagabundos, delinquentes, prostitutas, mendigos, deserdados da família, mães solteiras e marginais de toda ordem) (Lavor, 2008). Assim, Barbacena é conhecida nacionalmente como "Cidade dos Loucos", pela histórica concentração local de instituições psiquiátricas, públicas e privadas.

$\mathrm{Na}$ história da cidade, as elevadas taxas de óbito do hospital psiquiátrico apontam para as péssimas condições dos internos (Esteves, 1999). As primeiras denúncias de maus-tratos surgiram na imprensa em 1958, mas somente na década de 1970, em virtude da reação dos profissionais de saúde, jornalistas e intelectuais, iniciou-se a reavaliação das condições de tratamento vigentes. Especificamente com a criação da Fhemig em 1978, do documentário "Em nome da razão" de Helvécio Ratton, que retratava as condições indignas de vida e tratamento dos pacientes do Hospital Colônia de Barbacena (1979), e da série de reportagens de Hiram Firmino publicadas no jornal Estado de Minas (1979) iniciaram-se as primeiras medidas a fim de mudar essa realidade. A partir de 1986, inicia-se a democratização da instituição, com exten- 
sa reforma nos pavilhões e construção de módulos residenciais. Em 1993, ocorre a desativação da última cela do hospital (Vidal; Bandeira; Gontijo, 2008).

Ressalta-se que na $3^{a}$ edição do Festival, em 2008, ocorreu a promulgação do resultado do Concurso Público do Memorial das Rosas, que tinha como objetivo valorizar a história com elemento positivo (Beghini, 2007; Nunes Filho, 2008). O concurso destinava-se à construção de um memorial no antigo cemitério onde os pacientes do manicômio foram enterrados. O projeto vencedor configura-se como um monumento contra o preconceito, com a criação de um mirante e de um espaço para eventos cercados por rosas brancas. Estas são uma referência turística da cidade, pois Barbacena também é reconhecida como "Cidade das Rosas" (Lavor, 2008).

Muitas cidades utilizam os festivais como oportunidade de divulgação da cultura regional e identidade local (Petitinga, 2008; Rodrigues Júnior, 2008). $\mathrm{Na}$ literatura turística é possível constatar que os residentes das cidades percebem dois benefícios fundamentais advindos do desenvolvimento do turismo na região. O primeiro aponta que o turismo possibilita contato com outras culturas, podendo resultar em tolerância e conhecimento socioculturais. $\mathrm{O}$ segundo reside no fato de que, ao apresentar a cultura a um visitante, o turismo pode fortalecer o significado de morar naquela comunidade, contemplando a identidade cultural e orgulho comunitário e contribuindo para a coesão social (Besculides et al., 2002 apud Petitinga, 2008).

Os festivais podem impactar de maneira positiva ou negativa a comunidade em que estão inseridos. Não é objetivo deste trabalho analisar os impactos negativos relativos ao Festival da Loucura, pois se optou por enumerá-los para futuras pesquisas. A literatura aponta, entre os impactos negativos, que quanto maior o fluxo de turistas maior será a probabilidade de surgirem problemas. Entre os mais frequentes encontram-se a descaracterização da cultura local provocada pelo interesse comercial, a depredação do patrimônio histórico, a degradação social em consequência do consumo exagerado de drogas e a frustração da população local por não poder ter acesso e/ou usufruir hábitos e bens trazidos ou mesmo consumidos pelos turistas (Fontenele Júnior, 2004). De acordo com os visitantes, citam-se também como problemas comuns aos eventos a presença de multidões, as lon- gas filas, as precárias condições sanitárias, a falta de estacionamentos, as poucas informações disponíveis, os custos excessivos e a baixa qualidade de produtos, serviços ou atrações (Petitinga, 2008). Por último encontram-se os problemas de natureza ambiental, em geral visíveis apenas em longo prazo: buracos abertos nas ruas e estradas, causados pelo grande fluxo de veículos, a falta de água e luz, poluição do ar e da água (Fontenele Júnior, 2004).

\section{Considerações finais}

Pode-se concluir que a cultura é um meio de renovação e mudança de um grupo social e que, com o Plano Nacional de Cultura, o governo objetiva valorizar o patrimônio cultural brasileiro e propiciar o seu desenvolvimento da cultura no país. Assim, entre as formas de implementação do plano, pode-se encontrar a realização de festivais. Estes são eventos culturais que proporcionam à comunidade local uma programação cultural diversificada, ao longo de curto período de tempo, com atrações capazes de influenciar a imagem do local.

O Festival da Loucura caracteriza-se como evento cultural de Barbacena e região, e surge como protótipo de novas práticas e ações que utilizam a linguagem artística para a inclusão e democratização cultural, associadas à transformação do imaginário social sobre a loucura. Neste caso, as edições do Festival podem sensibilizar a sociedade no tocante à preservação da história da cidade e desmitificar a doença, além de reafirmar o processo da Reforma Psiquiátrica e seus princípios éticos de inclusão, solidariedade e cidadania. Entende-se que a diversidade de práticas culturais presentes no Festival da Loucura pode propiciar a moradores e visitantes momentos de aprendizagem, descontração, lazer, inclusão social e turismo cultural.

Por fim, ressalta-se a importância da realização de pesquisas de avaliação da recepção e significado do Festival da Loucura por parte dos grupos locais, para que não se reduza o evento como mais um caso de urbe, que se apropria do estigma e da identidade deteriorada para atrair fluxos de pessoas e, consequentemente, reverter o ressentimento por décadas de imagem degradada. 


\section{Referências}

AMARANTE, Paulo. Loucura, cultura e subjetividade: conceitos e estratégias, percursos e atores da Reforma Psiquiátrica Brasileira. In: FLEURY, Sonia. Saúde $e$ Democracia: a luta do CEBES. São Paulo: Lemos Editorial, 1997. p. 163-185.

. Manicômio e loucura no final do século e do milênio. In: FERNANDES, Maria Inês Assumpção; SCARCELLI, Ianni Regia; COSTA, Eliane Silvia. Fim de século: ainda manicômios? São Paulo: IPUSP, 1999. p. 47-53.

Saúde Mental e Atenção Psicossocial. Rio de Janeiro: Fiocruz, 2008.

Reforma psiquiátrica e epistemologia. Caderno

Brasileiro de Saúde Mental, v.1, n.1, p. 1-7, 2009.

BEGHINI, Ricardo. Evento une saúde e arte. Estado de Minas, Belo Horizonte, p. 23, 14 abr. 2007.

BOTELHO, Isaura. Dimensões da cultura e políticas públicas. São Paulo em Perspectiva, v. 15, n. 2, p. 73-83, 2001.

; FIORE, Maurício. O uso do tempo livre e as práticas culturais na Região Metropolitana de São Paulo: relatório da primeira etapa da pesquisa. São Paulo: Cebrap, 2005.

BOTTI, Nadja Cristiane Lappann; TORRÉZIO, Michele Cecília Silva. Festival da loucura e a dimensão sociocultural da reforma psiquiátrica. Revista Psicologia $\mathcal{E}$ Sociedade, 2012. [no prelo].

BRASIL. Lei no 12.343/2010. Institui o Plano Nacional de Cultura - PNC, cria o Sistema Nacional de Informações e Indicadores Culturais - SNIIC e dá outras providências. Diário Oficial da República Federativa do Brasil, 2010a.

Cultura em números: anuário de estatísticas culturais. 2. ed. Brasília: Ministério da Cultura, 2010b. Metas do Plano Nacional de Cultura. Brasília: Ministério da Cultura, 2011a.

Guia dos Museus Brasileiros. Brasília: Instituto Brasileiro de Museus, 2011b.

BRENNER, Ana Karina; DAYRELL, Juarez; CARRANO, Paulo. Culturas do lazer e do tempo livre dos jovens brasileiros. In: ABRAMO, Helena Wendel; BRANCO, Pedro Paulo Martoni. (Org.). Retratos da Juventude Brasileira: análises de uma pesquisa nacional. São Paulo: Perseu Abramo, 2005. p. 175-214.

CALABRE, Lia. Políticas culturais no Brasil: balanço e perspectivas. In: III Encontro de Estudos Multidisciplinares em Cultura, Salvador. Anais... 2007 p. 1-18.

CANCLINI, Néstor García. Culturas híbridas. São Paulo: Edusp, 2000.

. O papel da cultura em cidades pouco sustentáveis. In: SERRA, Monica Allende (Org.) Diversidade cultural e desenvolvimento urbano. São Paulo: Iluminuras, 2005. p. 185-198.

CAZELLI, Sibele. Ciência, cultura, museus, jovens e escolas: quais as relações? Tese (Doutorado em Educação) -
Faculdade de Educação, Pontifícia Universidade Católica do Rio de Janeiro, Rio de Janeiro, 2005.

ESTEVES, Bernardo. Bárbaras cenas. Ciência Hoje. v. 26, n. 156, p. 50-53, 1999.

FONSECA, Duda. Cada um com sua loucura. O Tempo, Belo Horizonte, p. 13, 29 mar. 2006.

FONTENELE JÚNIOR, Armando Matos. Percepção socioambiental: a visão de turistas e residentes de Guaramiranga-CE. Dissertação (Mestrado em Desenvolvimento e Meio Ambiente). Departamento de Geologia, Universidade Federal do Ceará, 2004.

FOUCAULT, Michel. História da loucura - na Idade Clássica. 8 ed., São Paulo: Perspectiva, 2007.

IBGE - Instituto Brasileiro de Geografia e Estatística. Anuário estatístico brasileiro. Brasília: IBGE, 2010.

IPEA - Instituto de Pesquisas Econômicas Aplicadas. Sistema de Indicadores de Percepção Social (SIPS). Brasília: IPEA, 2010.

LAVOR, Carlile. $3^{\circ}$ Festival da Loucura: trem de doido, cidadania. Revista RADIS: comunicação em saúde. v. 70, p. 12-5, 2008.

MAGLIOLI, Ailton. Várias faces da loucura. Estado de Minas, Belo Horizonte, p. 43, 30 mar. 2006.

Além do normal. Estado de Minas, Belo Horizonte, p. 4, 15 jul. 2010.

MAGRO FILHO, João Baptista. A tradição da loucura. Belo Horizonte: Coopmed, 1992.

NUNES FILHO, Augusto. Elegia à loucura. Estado de Minas, Belo Horizonte, p. 5-6, 02 abr. 2008.

PASSOS, Izabel Christina Friche. Cartografia da publicação brasileira em saúde mental: 1980-1996. Psicologia: Teoria e Pesquisa, v. 19, n. 3, p. 231-240, 2003.

PELEGRINI, Liliane. De perto ninguém é normal. $O$ Tempo, Belo Horizonte, p. 11, 11 abr. 2007.

PEREIRA, Lucimar. Histórico do Centro Hospitalar Psiquiátrico de Barbacena, 2009. Disponível em: <http:// www.museudapsiquiatria.org.br/predios_famosos/ exibir/?id=1>. Acesso em: $5 \mathrm{dez} .2011$.

PETITINGA, Carolina Santos. Festival de verão Salvador: significados para o turismo, a música independente, a economia e o marketing da cidade. Dissertação (Mestrado em Comunicação). Faculdade de Comunicação, Universidade Federal da Bahia, 2008.

REIS, Sérgio Rodrigues. Inverno nas Gerais. Estado de Minas, Belo Horizonte, p. 16-17, 10 jul. 2009.

RESENDE, Douglas. Celebração da loucura. O Tempo, Belo Horizonte, p. 3, 03 abr. 2008.

Loucura da mulher celebrada. O Tempo, Belo Horizonte, p. 3, 08 jul. 2009.

Festival da Loucura dá início a sua programação.

O Tempo, Belo Horizonte, p. 5, 15 jul. 2010.

RODRIGUES JÚNIOR, José Maria. Festival estudantil SESI Sorocaba de teatro. Dissertação (Mestrado em 
Comunicação). Escola de Comunicação e Artes, Universidade de São Paulo, São Paulo, 2008.

SANDER, Jardel. A caixa de ferramentas de Michel Foucault, a reforma psiquiátrica e os desafios contemporâneos. Psicologia E Sociedade, v. 22, n. 2, p. 38287, 2010.

SILVA, Lucimar Pereira (2009). Histórico do Centro Hospitalar Psiquiátrico de Barbacena. Disponível em: <http://www.museudapsiquiatria.org.br/predios_ famosos/exibir/?id=1>. Acesso em: 05 dez. 2011

SILVA, Frederico Barbosa; ARAÚJO, Herton Ellery; SILVEIRA, André Luis. Cultura, consumo e direitos. In: Economia e Política Cultural: acesso, emprego e financiamento. Brasília: IPEA, 2007.

VIDAL, Carlos Eduardo Leal; BANDEIRA, Marina; GONTIJO, Eliane Dias. Reforma psiquiátrica e serviços residenciais terapêuticos. Jornal Brasileiro de Psiquiatria, v. 57, n. 1, p. 70-79, 2008.

\title{
Madness Festival and the promotion of cultural practices
}

\begin{abstract}
In Brazil there is an urgent need to reverse the process of exclusion, the largest part of public consumption and opportunities for cultural creation. Cultural diversity brings forth the question of cultural democratization. This article aims to reflect on what aspect of the Madness Festival can contribute to the promotion of cultural practices and to the cultural democratization. The Festival editions have incentives to cultural practices related to museum and cultural center visits, visual arts exhibition, national and/or international film projection, theatrical presentation and music show. The Madness Festival is characterized as a cultural event that provides the local community a diverse cultural program over a short period of time, through attractions that can influence the place image and create opportunities for inclusion and cultural democratization.
\end{abstract}

Key-words: culture, inclusion, festival, mental health.

\section{El Festival de la Locura y la promoción de las prácticas culturales}

\section{Resumen}

En Brasil existe una urgente necesidad de revertir el proceso de exclusión, la mayor parte del consumo público y las oportunidades para la creación cultural. La diversidad cultural trae consigo la cuestión de la democratización cultural. En este artículo se pretende reflexionar sobre qué aspecto del Festival de la Locura puede contribuir a la promoción de las prácticas culturales y la democratización cultural. Las ediciones del Festival tienen incentivos para las prácticas culturales relacionadas con la visita al museo y centro cultural, una exposición de artes visuales, proyecciones de películas nacionales y / o extranjeras, la presentación teatral y espectáculo musical. El Festival de la Locura se caracteriza por ser un evento cultural que ofrece a la comunidad local de un variado programa cultural, en un corto período de tiempo, a través de atractivos que pueden influir en la imagen del sitio y crear oportunidades para la inclusión y la democratización cultural.

Palabras-clave: cultura, inclusión, festival, salud mental.

Data de recebimento do artigo: 29/5/12

Data de aprovação do artigo: 19/9/2012 